\title{
Alternative adjustment for seasonality and long-term time-trend in time-series analysis for long-term environmental exposures and disease counts
}

\author{
Honghyok Kim ${ }^{1 *}$, Jong-Tae Lee ${ }^{2,3}$, Kelvin C. Fong ${ }^{1}$ and Michelle L. Bell ${ }^{1}$
}

\begin{abstract}
Background: Time-series analysis with case-only data is a prominent method for the effect of environmental determinants on disease events in environmental epidemiology. In this analysis, adjustment for seasonality and long-term time-trend is crucial to obtain valid findings. When applying this analysis for long-term exposure (e.g., months, years) of which effects are usually studied via survival analysis with individual-level longitudinal data, unlike its application for short-term exposure (e.g., days, weeks), a standard adjustment method for seasonality and longterm time-trend can extremely inflate standard error of coefficient estimates of the effects. Given that individuallevel longitudinal data are difficult to construct and often available to limited populations, if this inflation of standard error can be solved, rich case-only data over regions and countries would be very useful to test a variety of research hypotheses considering unique local contexts.
\end{abstract}

Methods: We discuss adjustment methods for seasonality and time-trend used in time-series analysis in environmental epidemiology and explain why standard errors can be inflated. We suggest alternative methods to solve this problem. We conduct simulation analyses based on real data for Seoul, South Korea, 2002-2013, and time-series analysis using real data for seven major South Korean cities, 2006-2013 to identify whether the association between long-term exposure and health outcomes can be estimated via time-series analysis with alternative adjustment methods.

Results: Simulation analyses and real-data analysis confirmed that frequently used adjustment methods such as a spline function of a variable representing time extremely inflate standard errors of estimates for associations between long-term exposure and health outcomes. Instead, alternative methods such as a combination of functions of variables representing time can make sufficient adjustment with efficiency.

(Continued on next page)

\footnotetext{
* Correspondence: honghyok.kim@yale.edu

'School of the Environment, Yale University, 195 Prospect Street, New Haven,

CT 06511, USA

Full list of author information is available at the end of the article
}

(c) The Author(s). 2021 Open Access This article is licensed under a Creative Commons Attribution 4.0 International License, which permits use, sharing, adaptation, distribution and reproduction in any medium or format, as long as you give appropriate credit to the original author(s) and the source, provide a link to the Creative Commons licence, and indicate if changes were made. The images or other third party material in this article are included in the article's Creative Commons licence, unless indicated otherwise in a credit line to the material. If material is not included in the article's Creative Commons licence and your intended use is not permitted by statutory regulation or exceeds the permitted use, you will need to obtain permission directly from the copyright holder. To view a copy of this licence, visit http://creativecommons.org/licenses/by/4.0/. The Creative Commons Public Domain Dedication waiver (http://creativecommons.org/publicdomain/zero/1.0/) applies to the data made available in this article, unless otherwise stated in a credit line to the data. 


\begin{abstract}
(Continued from previous page)
Conclusions: Our findings suggest that time-series analysis with case-only data can be applied for estimating longterm exposure effects. Rich case-only data such as death certificates and hospitalization records combined with repeated measurements of environmental determinants across countries would have high potentials for investigating the effects of long-term exposure on health outcomes allowing for unique contexts of local populations.
\end{abstract}

Keywords: Case-only data, Long-term exposure, Time-series analysis, Seasonality, Time-trend, Environmental exposure

\section{Background}

Time-series analysis is a prominent method to estimate the effect of short-term (e.g., days, weeks) environmental exposures (e.g., air pollution, extreme weather) on health outcomes $[1,2]$. Time-series studies form the basis for our understanding of environmentally susceptible populations and the number of adverse health outcomes that can be potentially avoided if an adverse exposure level were to be reduced. Time-series data can consist of case-only records such as death certificates, hospitalization records, and insurance claims. So, time-series analysis with rich case-only data worldwide can contribute to not only the identification of the relationships between environmental exposures and a variety of health outcomes but also the improvement of generalizability of scientific findings, given that it is common that the health effects of environmental exposure are heterogeneous across regions and countries due to numerous modifiers such as demographics, socioeconomic positions and health behaviors [3-6]. For example, a recent study collected time-series data for mortality and air pollution over 652 cities across 24 countries [4] and found that the mortality effect of short-term exposure to air pollution may differ by countries.

In addition to short-term exposure effects, some environmental exposures, such as air pollution, have longterm (e.g., several months, years) exposure effects on health. These effects that are generally stronger than short-term exposure effects are usually investigated via cohort data. In cohort studies, exposure is estimated over long time periods, often accounting for mobility of study participants [1]. Cohort data with location information over time allow for more accurate assessment of exposure over long-time frames as participants are followed throughout time and changes in residence, which could affect exposure. However, cohort data are costly and difficult to construct, available for limited populations, and sometimes not representative for the general population so that generalizability for the magnitude of exposure effects is often limited: for example, most of the published air pollution cohort studies for Western countries, several for East Asian countries, and none for the rest of the world [6]. In contrast, registry data, such as death certificates and hospitalization records, are rich in many countries, but usually do not have information for mobility. This leads to higher potential exposure misclassification in studies of long-term exposure compared to studies of short-term exposure, which assume that participants had the same exposure for a few days prior to the event. Nevertheless, for general populations, such exposure misclassification is likely to result in underestimation $[7,8]$, which would be a basis of the conservative view if case-only data are used for inferring long-term exposure effects (i.e., understating the effects rather than overstating them).

A critical challenge for applying time-series analysis with case-only data into estimating the effect of long-term exposure on health outcomes is to adjust for seasonality and long-term time-trend. Unlike its application for shortterm exposure, adjustment for seasonality and long-term time-trend may mask a real signal of the effect of longterm exposure on an health outcome $[9,10]$ and can greatly reduce temporal variability of residual time-series of long-term exposure that is necessary to detect the signal [11]. So, the adjustment can inflate standard error of estimates, which make it difficult to make an inference of the effect of interest. In this regard, time-series studies in environmental epidemiology have been generally focused on short-term exposure, usually of a few days, at most about 40-60 days of an exposure time-window [10, 12 17]. In this paper, we address issues of adjustment for seasonality and long-term time-trend in estimating the effects of long-term exposure on health outcomes.

In the following sections, we discuss adjustment methods frequently used in time-series studies and identify possible problems in estimating the effect of longterm exposure when such methods are used. To solve these problems, we suggest alterative adjustment methods. We present statistical simulations and real data analysis to demonstrate that the effects of long-term exposure can be estimated via time-series analysis with alternative adjustment methods.

\section{Methods \\ Model formulation}

Suppose that an individual's hazard is estimated by a multiplicative hazard model with exposure variables, and 
a study population is a general population that can be seen as an open cohort. For shared environmental exposure over all individuals in a study population at time $t$ and $X_{t}$, population-averaged effect can be estimated using Poisson regression model with aggregated-level time-series data as follows [18]:

$$
\begin{aligned}
\log \left(E\left[Y_{t}\right]\right)= & \alpha+e\left(X_{t}, \ldots, X_{t-L}\right)+f\left(Z_{t}, \ldots, Z_{t-K}\right) \\
& +g(t)
\end{aligned}
$$

where $Y$ is the number of events and $Z$ is a set of measured potential confounders such as temperature (for air pollution studies), relative humidity, and influenza epidemic. $e\left(X_{t} \ldots, X_{t-L}\right)$ is a function of the populationaveraged effect of $X$ from $\operatorname{lag} 0$ (same day) to $\operatorname{lag} L$ (i.e., cumulative exposure for $L+1$ days) on $Y$. In the distributed lag model framework [19], this function is generalized to $\sum_{l=0}^{L} \beta_{l} X_{t-l}$. The overall cumulative coefficient (i.e., the logarithm of the overall cumulative relative rate/risk) is $\bar{\beta}=\sum_{l=0}^{L} \beta_{l}$. In practice, an observable $e\left(X_{t} \ldots, X_{t-L}\right)$ may not be equal to $e\left(X_{t} \ldots, X_{t-L}\right)$ due to mortality displacement and/or an exposure measurement error $[20,21] . g(t)$ is a function of the populationaveraged effect of unmeasured risk factors that shape seasonality and time-trend in a time-series of $Y$ [18]. Since $X$ has seasonality and time-trend, confounding could arise. To control for this confounding, several techniques have been used in the time-series literature. We discuss them in the context of estimating the effect of long-term $X$ (i.e., $X_{t} \ldots, X_{t-L}, L>$ months or years) on $Y$.

\section{Adjustment for seasonality and long-term time-trend Detrending prior to regression}

Prior to a regression analysis, seasonality and time-trend in an exposure series and an outcome series can be decomposed or removed by algorithms [14, 22, 23]. Detrended time-series can be used to estimate the effect of short-term $X$ on $Y$.

For estimating the effect of long-term $X$ on $Y$, detrending prior to regression is more challenging because a real signal of the effect of long-term $X$ on $Y$ may also be removed. For example, detrending a time-series of $Y$ will remove some long-term fluctuation of $Y$ that is formed by $\sum_{l=0}^{L} \beta_{l} X_{t-l}$. Consequently, an estimate of the effect of long-term $X$ on $Y$ would be biased toward the null.

\section{Adjustment in regression models}

Many time-series studies in environmental epidemiology adjust for seasonality and long-term time-trend by adding a variable or a set of variables representing time $(t)$ into regression models $[1,2,11,24]$. Natural cubic splines (NCS) with some degrees of freedom (df) per year are frequently used, and its performance for adjustment was tested by simulation studies [24-26]. We use
$\mathrm{NCS}(t, p \mathrm{df} /$ year $)$ to denote this in generalized linear models where $t$ represents a variable representing time and $p$ reflects the degrees of freedom. Non-parametric splines in generalized additive models are also frequently used, but for simplicity, we focus on the former as they may provide less biased estimates [11, 24]. In mortality studies, 3-8df/year is often used [24, 26, 27], but the optimal df may decrease depending on whether other variables explain seasonality to some extent (e.g., influenza epidemic, heat wave) are included in models [27].

Often, a combination of some variables is used [28, 29], such as NCS of calendar time of the year called day of the year (or day of the season) and an indicator of year (i.e., dummy variables) or equivalent (e.g., NCS of year). We use NCS(doy,pdf) $+\mathrm{I}$ (year) to denote NCS of day of the year (doy) and an indicator of year. But, NCS(doy,pdf) may not allow for seasonality that may vary between years. To address this, we additionally consider an NCS of the order of week throughout a study period, NCS(week,qdf) or an NCS of the order of month throughout a study period NCS(month, $r \mathrm{df}) . \quad \mathrm{NCS}(\mathrm{doy}, p \mathrm{df})+\mathrm{I}($ year) + $\mathrm{NCS}($ week, $q \mathrm{df})+\mathrm{NCS}$ (month, $r \mathrm{df}$ ) can collectively capture seasonality and long-term time-trend.

To present comparison between these functions, we smoothed daily time-series of $\mathrm{PM}_{10}$ and mortality in Seoul, South Korea, 2002-2013 through NCS with various degrees of freedoms (Fig. 1). Hourly measurement of $\mathrm{PM}_{10}$ concentration and all-cause mortality (International Classification of Diseases-10th, A00-R99) were obtained from the National Institute of Environmental Research and Statistics Korea, respectively, and hourly measurements from multiple monitors within Seoul on a given day were averaged. Figure 1 shows that $\mathrm{NCS}(t, 4 \mathrm{df} /$ year) can capture seasonality and long-term time-trend. $\mathrm{NCS}(t, 10 \mathrm{df} /$ year $)$ can further capture fluctuations more aggressively, which in cases of all-cause mortality, may be related to other environmental exposures such as heat waves [27]. NCS(doy,10df) $+\mathrm{I}$ (year) + NCS(week, $5 \mathrm{df})+\mathrm{NCS}($ month,5df) also captures seasonality and long-term time-trend although there are some differences compared to $\mathrm{NCS}(t, 10 \mathrm{df} /$ year): for example, a peak around 3300 time point (i.e., day). Such differences may be captured using additional dummy variables.

In estimating the effect of long-term $X$ on $Y$, standard errors can become very high, so that unstable estimates or spuriously significant estimates can come out. This is often referred to as overfitting as analogous of collinearity problems. To illustrate overfitting, we regressed a one-year moving average of $\mathrm{PM}_{10}$ concentration in Seoul, 2002-2013 on functions of variables representing time. Table 1 presents variance of residuals of this moving average and $R^{2}$. NCS $(t, 4 \mathrm{df} /$ year $)$ explains nearly all variability of the moving average $\left(R^{2}=99.3 \%\right)$. In comparison to $\mathrm{NCS}(t, 4 \mathrm{df} /$ year $)$ and $\mathrm{NCS}(t, 10 \mathrm{df} /$ year $)$, 


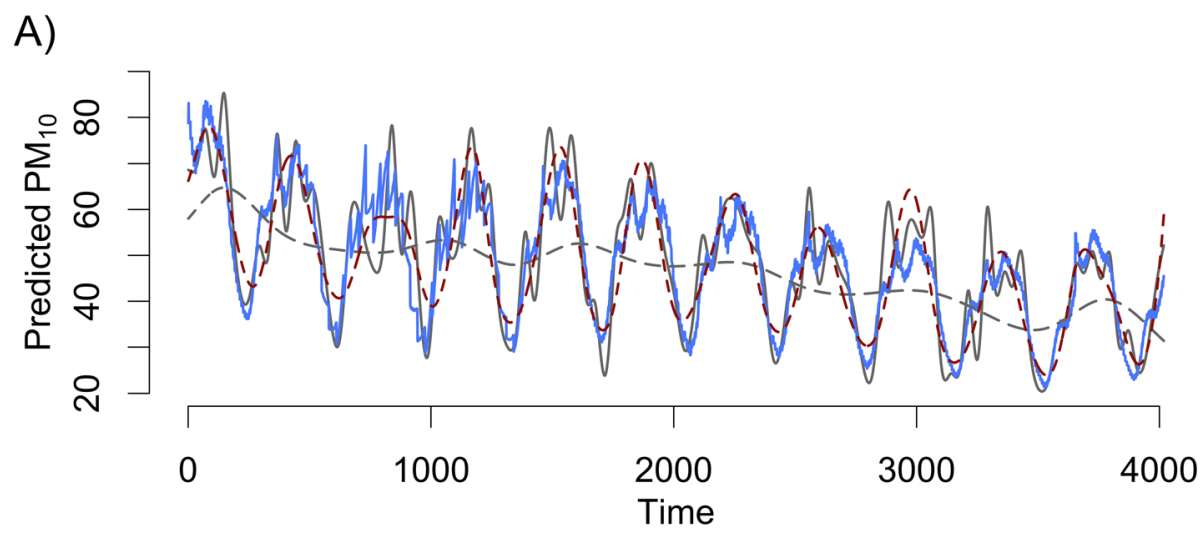

B)
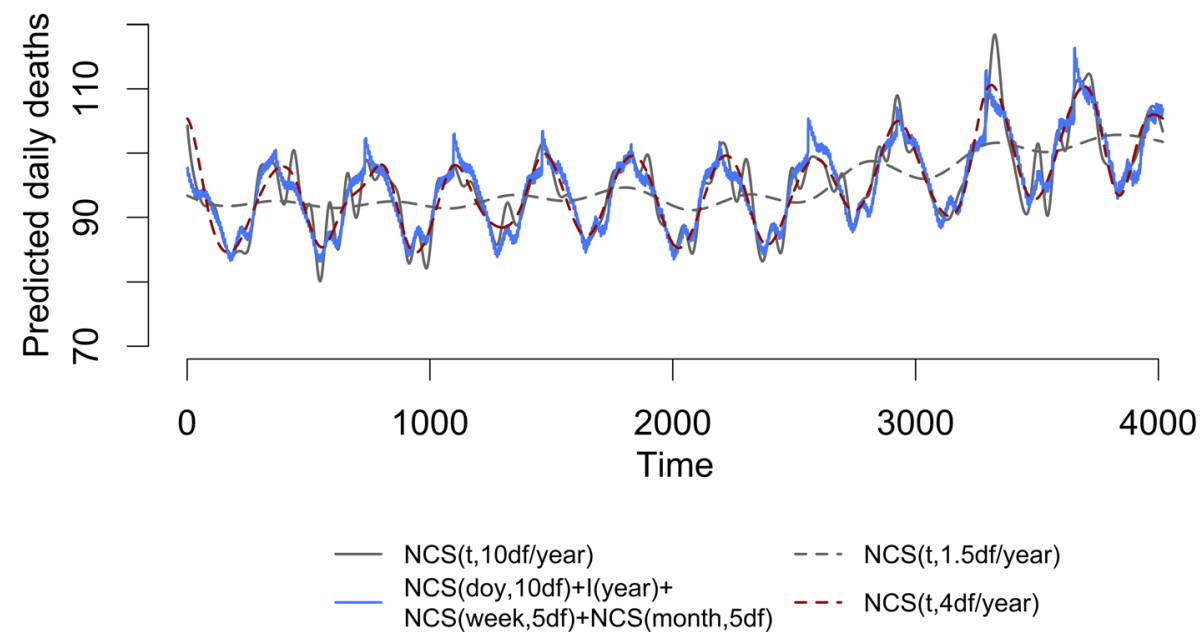

Fig. 1 Seasonality and time-trend in daily time-series in Seoul, 2002-2013. a $\mathrm{PM}_{10}$ concentration $\left(\mu \mathrm{g} / \mathrm{m}^{3}\right)$. b all-cause mortality (number of deaths/day), estimated by different functions of variables representing time. Abbreviation: df, degrees of freedom; doy, day of the week; NCS, natural cubic spline; I(year), an indicator function of year throughout the study period; NCS(doy,10df), NCS of day of the year with 10df; $\mathrm{NCS}($ month, $5 \mathrm{df})$, NCS of the order of month throughout the study period with $5 \mathrm{df}$; NCS(t,pdf/year), NCS of time throughout the study period with pdf per year; $\mathrm{NCS}($ week, $5 \mathrm{df})$, NCS of the order of week throughout the study period with $5 \mathrm{df}$; $\mathrm{PM}_{10}$, particulate matter with aerodynamic diameter $\leq 10 \mu \mathrm{m}$

Table 1 Residual variance of one-year moving average of $\mathrm{PM}_{10}$ concentration in Seoul, South Korea, 2002-2013

\begin{tabular}{lll}
\hline Adjustment method for seasonality and long-term time-trend & Residual variance & $\boldsymbol{R}^{\mathbf{2}}(\%)$ \\
\hline Not adjusted & 71.080 \\
$\mathrm{NCS}(t, 10 \mathrm{df} /$ year) & 0.185 \\
$\mathrm{NCS}(t, 4 \mathrm{df} /$ year) & 0.505 \\
$\mathrm{NCS}(t, 1.5 \mathrm{df} /$ year) & 1.029 \\
$\mathrm{NCS}($ doy,10df)+l(year)+NCS(week,20df)+NCS(month,20df) & 0.675 \\
$\mathrm{NCS}($ doy,10df)+l(year)+NCS(week,5df)+NCS(month,5df) & 2.088 \\
$\mathrm{NCS}($ doy,10df)+l(year) & 2.417 \\
\hline
\end{tabular}

Abbreviations: $d f$ degrees of freedom, doy day of the year, I(year) an indicator function of year throughout the study period, NCS natural cubic spline, NCS(doy,pdf) NCS of doy with pdf, NCS(month,pdf) NCS of the order of month throughout the study period with pdf, NCS(t,pdf/year) NCS of time throughout the study period with pdf per year, NCS(week,pdf) NCS of the order of week throughout the study period with $p \mathrm{df}, P M_{10}$ particulate matter with aerodynamic diameter $\leq 10 \mu \mathrm{m}$ 
NCS(doy,10df)+I(year) and NCS(doy,10df)+I(year) $+\mathrm{NCS}$ (week,5df)+NCS(month,5df) explains to a lesser extent variability of the moving average $\left(R^{2}=96.6\right.$ and $97.1 \%$ respectively). The perhaps seemingly small difference in residual variances between these methods could make striking difference in standard errors. Assuming that there are no other covariates to be considered, standard errors may be approximately 17 times higher when $\mathrm{NCS}(t, 4 \mathrm{df} /$ year $)$ is used than when NCS(doy,10df) $+\mathrm{I}$ (year) $+\mathrm{NCS}$ (week,5df)+ $\mathrm{NCS}$ (month,5df) is used, which is based on a ratio of the two standard deviations of the residuals [30].

To maintain variability in residuals of long-term $X$ using $\mathrm{NCS}(t, p \mathrm{df} /$ year $)$, df needs to be reduced, but low df results in loss of adjustment for seasonality. For example, $\mathrm{NCS}(t, 1.5 \mathrm{df} /$ year $)$ does not adequately capture seasonality (Fig. 1b). Note that this function still captures variability of a one-year moving average of $\mathrm{PM}_{10}$ to a greater extent than $\mathrm{NCS}($ doy, $10 \mathrm{df})+\mathrm{I}($ year $)+\mathrm{NCS}$ (week, $5 \mathrm{df})+\mathrm{NCS}$ (month, $5 \mathrm{df}$ ) (Table 1). Thus, NCS(t,pdf/year) may not be relevant for estimating the effect of longterm $X$ on $Y$.

In summary, adjustment for seasonality and long-term time-trend should be made with avoiding reducing variability of $X$ to a great extent. $\mathrm{NCS}(t, p \mathrm{df} /$ year $)$ as a standard method in time-series studies appears inefficient. A candidate we explored is a combination of some variables such as $\mathrm{NCS}($ doy, $p \mathrm{df})+\mathrm{I}($ year) $+\mathrm{NCS}$ (week, $q \mathrm{df})+\mathrm{NCS}$ (month, $r \mathrm{df}$ ) with moderate $\mathrm{df}$. Simulations and real-data analyses were conducted to test this method.

\section{Confounding by long-term association}

Although our primary interest is to estimate the effect of long-term $X$ on $Y$, whether the effect of short-term $X$ on $Y$ (e.g., $\sum_{l=0}^{M} \beta_{l} \quad(M<$ few days or weeks $)$ can be confounded by long-term association (e.g., $\sum_{l=M}^{L} \beta_{l} X_{t-l}$ ) merits investigation in that neighboring lagged variables can have an confounding effect [31] and long-term association can be seen as an weighted moving average of $X$ that would contribute to seasonality and long-term time-trend of $Y$. If conventional adjustment for seasonality and a time-trend does not sufficiently adjust for longterm association, an inclusion of exposure variables may be needed. Simulations and real-data analyses were also conducted to explore confounding by long-term association.

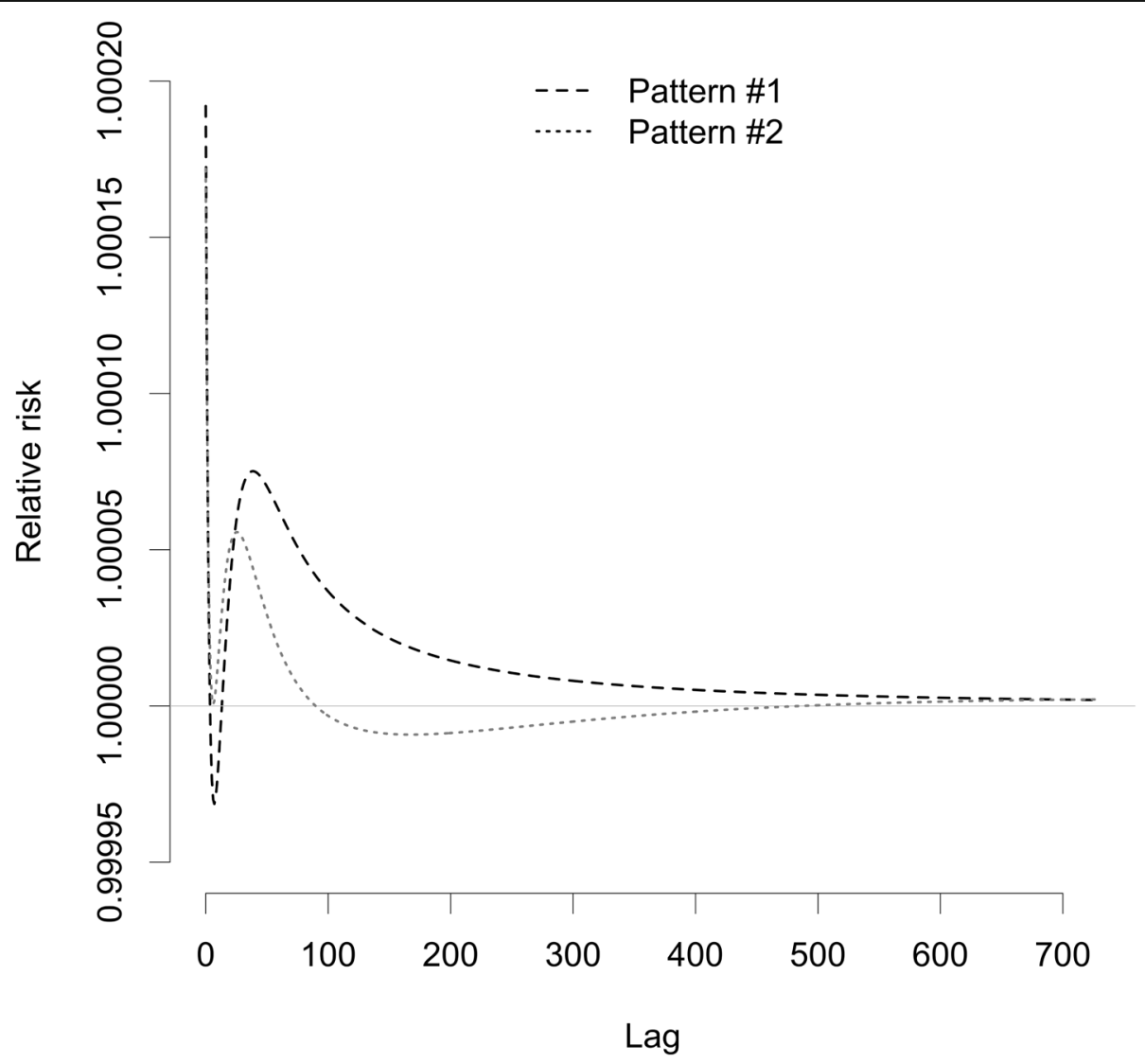

Fig. 2 Two hypothetical observable lag patterns of the association between $1 \mu \mathrm{g} / \mathrm{m}^{3}$ increase of exposure to $\mathrm{PM}_{10}$ and mortality, used to generate simulation samples. Abbreviation: $\mathrm{PM}_{10}$, particulate matter with aerodynamic diameter $\leq 10 \mu \mathrm{m}$ 


\section{Simulation methods}

We investigate performance of different functions to adjust for seasonality and long-term time-trend in estimating the effect of long-term $X$ on $Y$ using simulation analyses.

\section{Generating simulation samples}

Figure 2 shows two hypothetical observable lag patterns to generate simulation samples. The assumed overall cumulative coefficients were 0.01 and 0.001 per a $1 \mu \mathrm{g} / \mathrm{m}^{3}$ increase of $\mathrm{PM}_{10}$, for the observable lag patterns in Fig. 2a and b, respectively. We considered the effect of cumulative exposure on an outcome and mortality displacement; we did not consider exposure measurement errors. For example, epidemiologic evidence shows that the logarithm of the relative risk of the exposure to $\mathrm{PM}_{2.5}$ on mortality generally increases with the exposure duration (i.e., $L$ increases in the distributed lag model framework) while the highest marginal increase arises at the most proximal time of the exposure [32, 33]. We considered two distributions of decreases in mortality due to mortality displacement (Fig. S1 in Additional file 1). Findings of many time-series studies focused on short-term exposure to PM imply that observable lag patterns for short-term exposure to air pollutants and mortality are non-linear [10, 12, 13, 15$17,34]$ suggesting that short-term mortality displacement may play a role in shaping observable lag patterns.

We generated simulation samples for daily time-series of $\mathrm{PM}_{10}$ and mortality based on real data of Seoul, 2002-2013. For this, we regressed the logarithm of daily average of $\mathrm{PM}_{10}$ and the daily number of all-cause mortality cases (except for accidental causes) on functions of variables representing time and potential confounders in time-series studies, including a lag-structure of temperature from lag0-21, relative humidity, influenza epidemic, national holidays, and day of the week. For temperature and relative humidity, hourly measurements at the center of Seoul obtained from the Korean Meteorological Administration were averaged to daily values. Influenza epidemic was based on the number of hospital visits for influenza, which was obtained from the National Health Insurance System. To generate a time-series of $\mathrm{PM}_{10}$, values were sampled from normal distributions and then were exponentiated. A mean of normal distributions was predicted with values obtained from the regression model for the logarithm of $\mathrm{PM}_{10}$. Their standard deviation was estimated from the model (low concurvitiy) or the value divided by 10 (high concurvity) [24]. To generate time-series of all-cause mortality, the number of events were sampled from Poisson distributions. A mean of Poisson distributions was the sum of predicted values obtained from the Poisson regression model for all-cause mortality and a product of a lag pattern and distributed lags of generated $\mathrm{PM}_{10}$ series. Technical detail for this section is presented in Additional file 1. Fig. S2 in Additional file 1 shows an example of simulated sample of time-series.

\section{Testing models}

To adjust for seasonality and long-term time-trend in generated time-series samples, we used $\mathrm{NCS}(t, 4 \mathrm{df} /$ year $)$, $\mathrm{NCS}(t, 10 \mathrm{df} /$ year $), \quad$ and $\mathrm{NCS}($ doy,10df $)+\mathrm{I}($ year $)+$ $\mathrm{NCS}$ (week,5df)+NCS(month, 5df). We used constrained distributed lags of $\mathrm{PM}_{10}$ (lag0-730) to estimate the association between $\mathrm{PM}_{10}$ and mortality. We also used only two-day moving average of $\mathrm{PM}_{10}$ (lag0-1) to see whether the cumulative exposure to $\mathrm{PM}_{10}$ and mortality displacement (lag2-730) can have a confounding effect. We adjusted for a lag-structure of temperature, relative humidity, influenza epidemic, national holidays, and day of the week. Technical detail for this section is presented in Additional file 1.

\section{Methods for real data analysis}

We conducted a two-stage time-series analysis to estimate the effect of long-term exposure to $\mathrm{PM}_{10}$ on mortality in seven major cities (Seoul, Busan, Daegu, Incheon, Gwangju, Daejeon, and Ulsan) of South Korea from 2006 to 2013. Datasets are described in Additional file 2. In the first stage, we fitted city-specific Poisson regression models with overdispersion considered. Constrained distributed lags of $\mathrm{PM}_{10}$ (lag0-365) were used as an exposure metric. A lag-structure of temperature (lag0-14 or lag0-21), $\mathrm{O}_{3}$ (lag0-45), relative humidity, and influenza epidemic was adjusted. Seasonality and long-term time-trend were also adjusted using (a) $\mathrm{NCS}(t, p \mathrm{df} /$ year), (b) $\mathrm{NCS}(\mathrm{doy}, p \mathrm{df})+\mathrm{I}($ year $)$, or (c) $\mathrm{NCS}($ doy, $p \mathrm{df})+\mathrm{I}($ year$)+\mathrm{NCS}($ week, $p \mathrm{df})+\mathrm{NCS}($ month, $p \mathrm{df})$. Technical detail for modelling is provided in Additional file 2 . In the second stage, we applied multivariate metaanalysis to pool city-specific estimates [35]. We compared pooled estimates of the association between adjustments for seasonality and long-term time-trend. This procedure was to check possible overfitting.

As sensitivity analyses, we used different dfs in each NCS. We also additionally adjusted for multiple dummy variables indicating days when deviations of seasonality were identified. For this additional adjustment, we found that days when predicted daily deaths of a city-specific model with $\mathrm{NCS}($ doy,20df $)+\mathrm{I}($ year $)+\mathrm{NCS}($ week,3df $)+$ $\mathrm{NCS}$ (month,3df) and those of a city-specific model with $\mathrm{NCS}(t, 10 \mathrm{df} /$ year $)$ did not coincide one another; if deviations from normal seasonal patterns exist across years, these two models would yield different predicted daily deaths because $\mathrm{NCS}(t, 10 \mathrm{df} /$ year $)$ is likely to capture deviations better. We used cut-off values to determine deviations of seasonality: $\left|A_{t}-B_{t}\right|>$ a cut-off value where $A_{t}$ 
is predicted logarithm of daily deaths from one model and $B_{t}$ is predicted logarithm of daily deaths from the other model at time $t$. We varied a cut-off value from 98th percentile, 96th percentile, ..., to 80th percentile of $\left|A_{t}-B_{t}\right|$.

\section{Software}

We used R software 3.5.3 (R Foundation for Statistical Computing) for simulations and real-data analyses. We used splines package for NCS [36], dlnm package for distributed lags of $\mathrm{PM}_{10}$ and distributed lag non-linear terms of temperature [37], and mvmeta package for pooling city-specific estimates [35]. $\mathrm{R}$ codes for simulations and real-data analysis are provided in the first author's website, http://hkimresearch.com, or Github, https://github.com/HonghyokKim/

AlternativeAdjustment.

\section{Results}

\section{Results of simulations}

Table 2 presents bias, standard deviation, and nominal coverage of $95 \%$ confidence interval for the overall cumulative association between distributed lags of $\mathrm{PM}_{10}$ (lag0-730) and mortality. Models adjusted for NCS(doy, $10 \mathrm{df})+\mathrm{I}($ year $)+\mathrm{NCS}$ (week, $5 \mathrm{df})+\mathrm{NCS}($ month, $5 \mathrm{df}) \quad$ produced estimates of the overall cumulative coefficient with negligible bias and almost perfect coverage of 95\% confidence intervals (Table 2). Lag patterns were estimated accurately (Fig. 3). As expected by very small residual variance of $\mathrm{PM}_{10}$ as in Table 1 , models adjusted for $\mathrm{NCS}(\mathrm{t}, 4 \mathrm{df} /$ year) and $\mathrm{NCS}(\mathrm{t}, 10 \mathrm{df} /$ year) produced very large standard errors, indicating overfitting. These models also produced lag-mortality associations that deviated far from lag patterns used to generate simulation samples (Fig. 3).

Our simulation results suggest that the effect of shortterm exposure to $\mathrm{PM}_{10}$ on all-cause mortality may be confounded by the effect of long-term exposure to $\mathrm{PM}_{10}$ on all-cause mortality in some circumstances. For example, for observable lag pattern \#2, bias with respect to a moving average of $\mathrm{PM}_{10}$ from lag0-1 in its relation with all-cause mortality was $-11.3 \%$ when $\mathrm{NCS}(t, 10 \mathrm{df} /$ year) was used and $\mathrm{PM}_{10}$ from lag2-730 was not adjusted (Table $\mathrm{S} 1$ in Additional file 1). When $\mathrm{PM}_{10}$ from lag2-730 was adjusted, the bias decreased to $2.8 \%$. The bias decreased with higher df. For observable lag pattern \#1, the bias decreased to $0.4 \%$ from $4 \mathrm{df}$ to $10 \mathrm{df}$ when $\mathrm{PM}_{10}$ from lag2-730 was not adjusted.

\section{Results of real-data analyses}

Table 3 presents percentage increases in all-cause mortality risk per a $10 \mu \mathrm{g} / \mathrm{m}^{3}$ increase in two-day moving average of $\mathrm{PM}_{10}$ (lag0-1) or $\mathrm{PM}_{10}$ for one-year (i.e., lag0-365) in seven major cities of South Korea. When $\mathrm{PM}_{10}$ (lag2-365) was adjusted, the percentage increases in all-cause mortality were $0.14 \%$ ( $95 \%$ confidence interval: $-0.06,0.34)$ for $\mathrm{NCS}(\mathrm{t}, 10 \mathrm{df} /$ year $)$ and $0.14 \%(-0.03$, $0.31)$ for $\mathrm{NCS}($ doy, $20 \mathrm{df})+\mathrm{I}($ year $)+\mathrm{NCS}($ week,3df $)+$ NCS(month,3df).

The percentage increase in all-cause mortality risk for a $10 \mu \mathrm{g} / \mathrm{m}^{3}$ increase of $\mathrm{PM}_{10}$ for 1 year (i.e., lag0-365) was $4.66 \%(0.14,9.38)$ when $\mathrm{NCS}($ doy, $20 \mathrm{df})+\mathrm{I}($ year $)+$ NCS(week,3df)+ NCS(month,3df) was used (Table 3). This percentage increase was stable when different $\mathrm{df}$

Table 2 Bias, standard deviation, nominal coverage of 95\% confidence interval for the overall cumulative association between distributed lags of $\mathrm{PM}_{10}$ (lag0-730) and all-cause mortality estimated by a model with different adjustment methods for seasonality and long-term time-trend over 10,000 samples of different simulation settings based on time-series data for Seoul, 2002-2013

\begin{tabular}{|c|c|c|c|c|c|c|c|}
\hline \multirow[t]{2}{*}{ Concurvity $^{a}$} & \multirow[t]{2}{*}{ Adjustment $^{\mathrm{b}}$} & \multicolumn{3}{|c|}{ Observable Lag Pattern $1^{a}$} & \multicolumn{3}{|c|}{ Observable Lag Pattern $2^{a}$} \\
\hline & & Bias (\%) & $\mathrm{SD}^{\mathrm{c}}$ & Coverage $^{\mathrm{d}}(\%)$ & Bias (\%) & $S^{c}$ & Coverage $^{d}(\%)$ \\
\hline \multirow[t]{4}{*}{ Low } & Not adjusted & -50.1 & 0.004 & 0 & -509.2 & 0.004 & 0 \\
\hline & $\mathrm{NCS}(t, 4 \mathrm{df} /$ year $)$ & 885.2 & 1.457 & 89.6 & 9259.9 & 1.459 & 88.9 \\
\hline & $\operatorname{NCS}(t, 10 \mathrm{df} /$ year $)$ & -2239.6 & 19.994 & 94.3 & $-21,974.9$ & 19.651 & 94.7 \\
\hline & $10,5,5$ & -0.5 & 0.047 & 95.0 & -2.6 & 0.047 & 94.9 \\
\hline \multirow[t]{4}{*}{ High } & Not adjusted & -54.1 & 0.003 & 0 & -549.4 & 0.003 & 0 \\
\hline & $\mathrm{NCS}(t, 4 \mathrm{df} /$ year $)$ & 1346.0 & 1.828 & 88.7 & $14,086.5$ & 1.825 & 87.9 \\
\hline & $\operatorname{NCS}(t, 10 \mathrm{df} /$ year $)$ & -496.0 & 24.822 & 94.9 & -2649.2 & 24.971 & 94.6 \\
\hline & $10,5,5$ & -0.4 & 0.056 & 94.8 & 2.9 & 0.055 & 95.0 \\
\hline
\end{tabular}

Abbreviations: $d f$ degrees of freedom, NCS natural cubic spline, NCS(t,pdf/year) NCS of time throughout the study period with $p d f$ per year, $P M_{10}$ particulate matter with aerodynamic diameter $\leq 10 \mu \mathrm{m}, S D$ standard deviation

${ }^{a}$ Simulation settings: Low concurvity \& Observable lag pattern 1, Low concurvity \& Observable lag pattern 2, High concurvity \& Observable lag pattern 1, and High concurvity \& Observable lag pattern 2; Observable lag patterns 1-2 are provided in Fig. 2

${ }^{b} \mathrm{NCS}($ doy, $10 \mathrm{df})+\mathrm{I}($ year) $+\mathrm{NCS}$ (week, $5 \mathrm{df}$ )+NCS(month,5df) is described as 10,5,5; NCS(doy,10df) is NCS of day of the year with $10 \mathrm{df}$; I(year) is an indicator function of year throughout the study period; NCS(week, $5 \mathrm{df}$ ) is NCS of the order of week throughout the study period with $5 \mathrm{df}$; NCS(month,5df) is NCS of the order of month throughout the study period with $5 \mathrm{df}$

${ }^{\text {cSD }}$ of estimates of the overall cumulative coefficient (as $10 \mu \mathrm{g} / \mathrm{m}^{3}$ increase of $\mathrm{PM}_{10}$ )

${ }^{d}$ Nominal coverage of $95 \%$ confidence intervals 


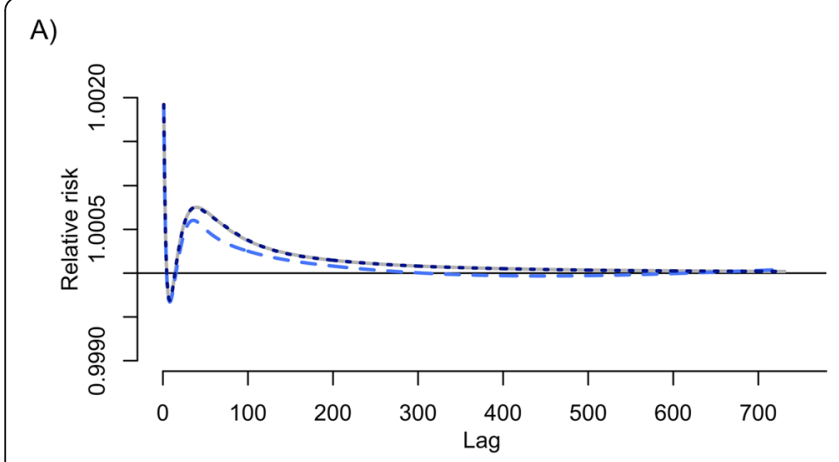

B)

C)

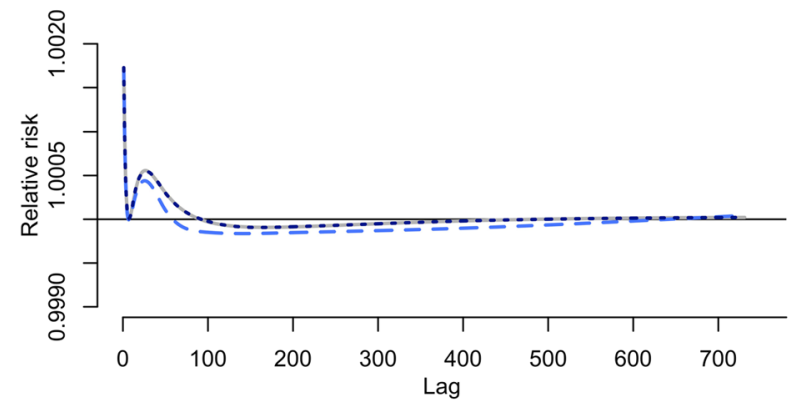

E)

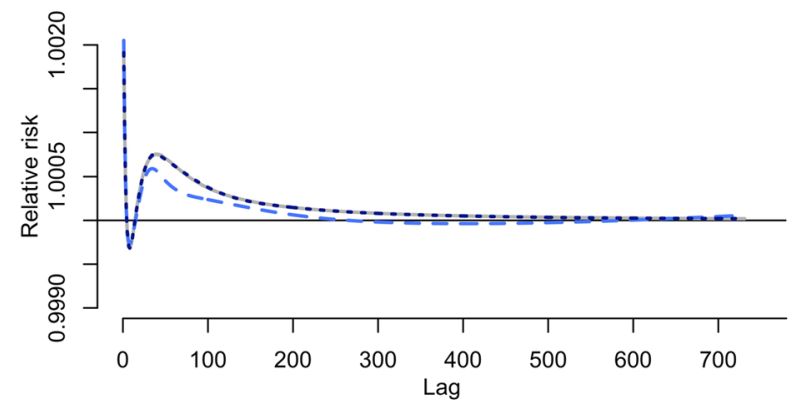

G)

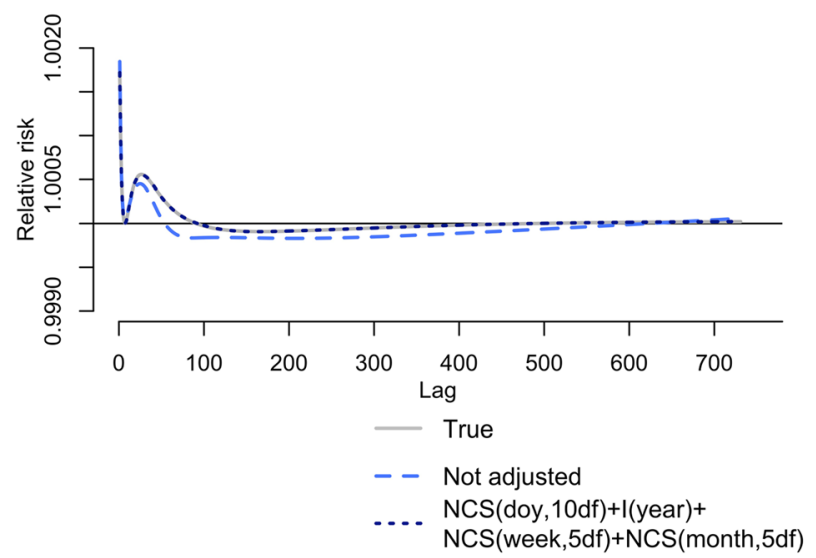

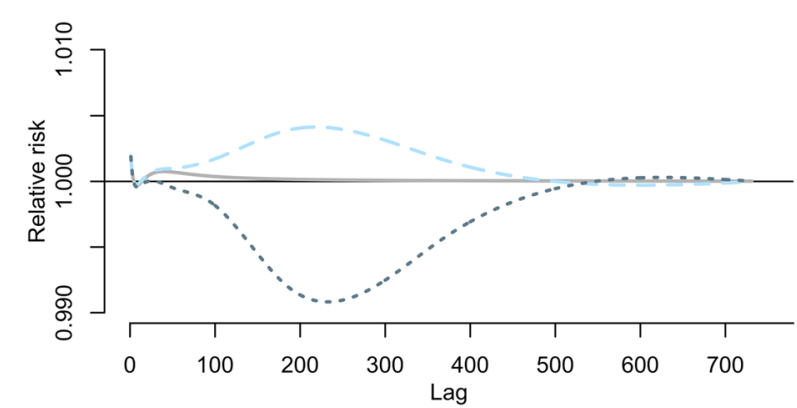

D)

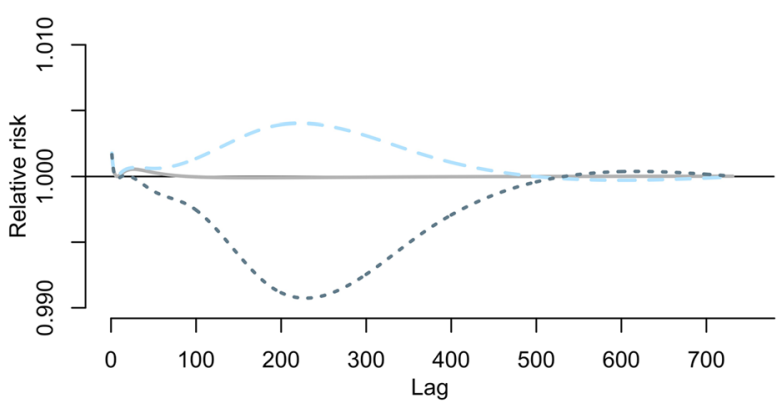

F)

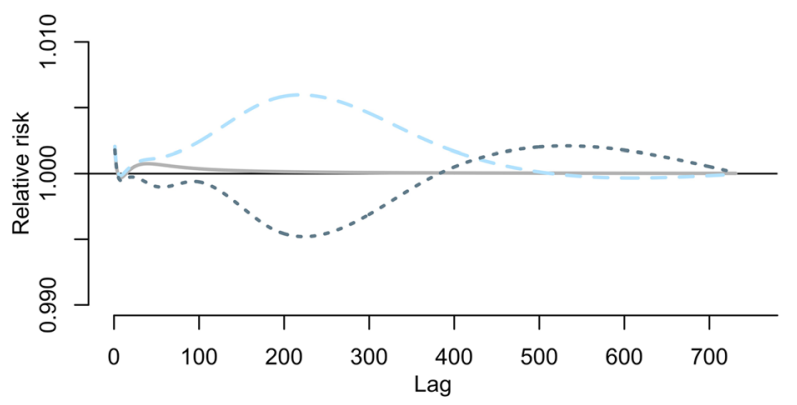

H)

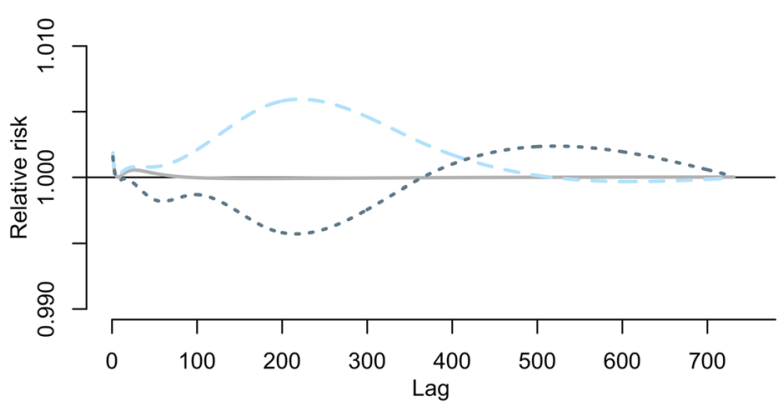

$\mathrm{NCS}(\mathrm{t}, 4 \mathrm{df} /$ year)

NCS(t,10df/year)

Fig. 3 (See legend on next page.) 
(See figure on previous page.)

Fig. 3 Estimated lag patterns of the association between $\mathrm{PM}_{10}$ and all-cause mortality by different methods to adjust for seasonality and timetrend over 5000 samples of different simulation settings based on time-series data for Seoul, 2002-2013. a and b Low concurvity and Observable lag pattern 1. $\mathbf{c}$ and $\mathbf{d}$ Low concurvity and Observable lag pattern 2. e and $\mathbf{f}$ High concurvity and Observable lag pattern 1. $\mathbf{g}$ and $\mathbf{h}$ High concurvity and Observable lag pattern 2. Abbreviation: df, degrees of freedom; doy, day of the week; I(year), an indicator function of year throughout the study period; NCS, natural cubic spline; NCS(doy,10df), NCS of day of the year with 10df; NCS(month,5df), NCS of the order of month throughout the study period with $5 \mathrm{df}$; NCS(t,10df/year), NCS of time throughout the study period with 10df per year; NCS(week,5df), NCS of the order of week throughout the study period with $5 \mathrm{df} ; \mathrm{PM}_{10}$, particulate matter with aerodynamic diameter $\leq 10 \mu \mathrm{m}$

were used for each NCS unless df were too high for $\mathrm{NCS}$ (week, $q \mathrm{df}$ ) and NCS(month, $r \mathrm{df}$ ). For example, estimates were variable with very wide confidence intervals for 6, 10, and $15 \mathrm{df}$ for each NCS (Table 3). When NCS(t, $p \mathrm{df} /$ year) was used, estimates across different $\mathrm{df}$ were extremely variable with very wide confidence intervals, indicating overfitting (Table 3). For cardiovascular mortality and respiratory mortality, we found similar patterns of estimates as those found for all-cause mortality. Percentage increase in cardiovascular mortality risk and respiratory mortality risk for a $10 \mu \mathrm{g} / \mathrm{m}^{3}$ increase of $\mathrm{PM}_{10}$ for 1 year was $10.76 \%(0.62,21.93)$ and $9.34 \%(-17.77,45.40)$, respectively (Tables S2-3 in Additional file 2).

Figure S3 in Additional file 2 presents an example of differences between time-series of predicted logarithm of daily deaths from city-specific models with NCS(doy, 20df) $+\mathrm{I}($ year $)+\mathrm{NCS}$ (week,3df) $+\mathrm{NCS}($ month, 3df) and city-specific models with $\mathrm{NCS}(t, 10 \mathrm{df} /$ year $)$. Since a lag- structure of temperature, air pollutants, and other variables such as influenza epidemics were all used, both models predicted daily mortality series similarly. Nevertheless, some deviations of seasonality were also identified: for example, about 1000-1250 time points (i.e., days) and around 1800 time point in Seoul (Fig. S3A). We adjusted for such deviations using multiple dummy variables and found our results robust to these additional adjustments (Fig. S4 in Additional file 2).

Figure 4 presents the percentage increase in all-cause mortality risk, cardiovascular mortality risk, and respiratory mortality risk by exposure duration. These increasing patterns reconcile previous observations that the association between exposure to PM and mortality increases with exposure duration: roughly similar to 5$15 \%$ increase of mortality per $20 \mu \mathrm{g} / \mathrm{m}^{3}$ increase of oneyear exposure to $\mathrm{PM}_{10}[32,33]$. Figure 5 presents corresponding lag patterns.

Table 3 Percentage increase and 95\% confidence intervals of all-cause mortality risk per a $10 \mu \mathrm{g} / \mathrm{m}^{3}$ Increase in two-day moving average of $\mathrm{PM}_{10}$ (lag0-1) or one-year distributed lags of $\mathrm{PM}_{10}$ (lag0-365) in seven major cities of South Korea, 2006-2013

\begin{tabular}{|c|c|c|c|c|c|c|}
\hline \multirow{3}{*}{$\begin{array}{l}\text { Adjustment method } \\
\text { for seasonality and } \\
\text { long-term time- } \\
\text { trend }\end{array}$} & \multicolumn{4}{|c|}{$\begin{array}{l}\text { Two-day moving average } \\
\text { (lag0-1) }\end{array}$} & \multirow{2}{*}{\multicolumn{2}{|c|}{$\begin{array}{l}\text { One-year distributed lags } \\
\text { (lag0-365) }\end{array}$}} \\
\hline & \multicolumn{2}{|c|}{ lag2-365 not adjusted } & \multicolumn{2}{|c|}{ lag2-365 adjusted } & & \\
\hline & $\overline{\mathrm{PI}}$ & $95 \% \mathrm{Cl}$ & $\overline{\mathrm{PI}}$ & $95 \% \mathrm{Cl}$ & $\overline{\mathrm{PI}}$ & $95 \% \mathrm{Cl}$ \\
\hline Not adjusted & -0.44 & $-0.71,-0.16$ & 0.08 & $-0.08,0.24$ & -9.46 & $-13.27,-5.48$ \\
\hline NCS(t,7df/year) & 0.16 & $0,0.31$ & 0.12 & $-0.06,0.31$ & 4.67 & $-51.66,126.62$ \\
\hline NCS(t,10df/year) & 0.15 & $-0.01,0.31$ & 0.14 & $-0.06,0.34$ & -20.60 & $-76.83,172.13$ \\
\hline $\mathrm{NCS}(\mathrm{t}, 12 \mathrm{df} /$ year $)$ & 0.15 & $-0.01,0.31$ & 0.20 & $-0.01,0.40$ & -35.64 & $-84.39,165.33$ \\
\hline NCS(doy, 20df)+I(year) & 0.13 & $-0.03,0.28$ & 0.17 & $0,0.33$ & 2.86 & $-2.13,8.10$ \\
\hline $10,3,3$ & 0.10 & $-0.05,0.26$ & 0.14 & $-0.05,0.34$ & 4.40 & $-0.10,9.11$ \\
\hline $20,3,3$ & 0.12 & $-0.04,0.27$ & 0.14 & $-0.03,0.31$ & 4.66 & $0.14,9.38$ \\
\hline $30,3,3$ & 0.12 & $-0.04,0.28$ & 0.15 & $-0.02,0.32$ & 4.64 & $0.07,9.41$ \\
\hline $20,4,4$ & 0.12 & $-0.03,0.28$ & 0.14 & $-0.03,0.31$ & 5.54 & $1.32,9.95$ \\
\hline $20,5,5$ & 0.11 & $-0.04,0.27$ & 0.12 & $-0.05,0.29$ & 4.55 & $-0.93,10.34$ \\
\hline $20,6,6$ & 0.08 & $-0.08,0.24$ & 0.09 & $-0.09,0.28$ & 0.50 & $-5.75,7.18$ \\
\hline $20,10,10$ & 0.08 & $-0.08,0.23$ & 0.12 & $-0.09,0.34$ & 5.45 & $-4.81,16.83$ \\
\hline $20,15,15$ & 0.09 & $-0.07,0.25$ & 0.13 & $-0.07,0.34$ & -4.72 & $-22.75,17.51$ \\
\hline
\end{tabular}

Abbreviations: $C l$ confidence interval, $d f$ degrees of freedom, doy day of the year, I(year) an indicator function of year throughout the study period, $N C S$ natural cubic spline, NCS(doy,pdf) NCS of doy with $p d f, N C S(t, p d f / y e a r)$ NCS of time throughout the study period with $p$ df per year, $P I$ percentage increase, $P M_{10}$ particulate matter with aerodynamic diameter $\leq 10 \mu \mathrm{m}$

${ }^{a} \mathrm{NCS}(\mathrm{doy}, p \mathrm{df})+\mathrm{I}$ (year)+NCS(week,qdf)+NCS(month,rdf) is described as $p, q, r ; \mathrm{NCS}$ (week,qdf) is NCS of the order of week throughout the study period with $q \mathrm{df}$; $\mathrm{NCS}$ (month,rdf) is NCS of the order of month throughout the study period with $r \mathrm{df}$ 


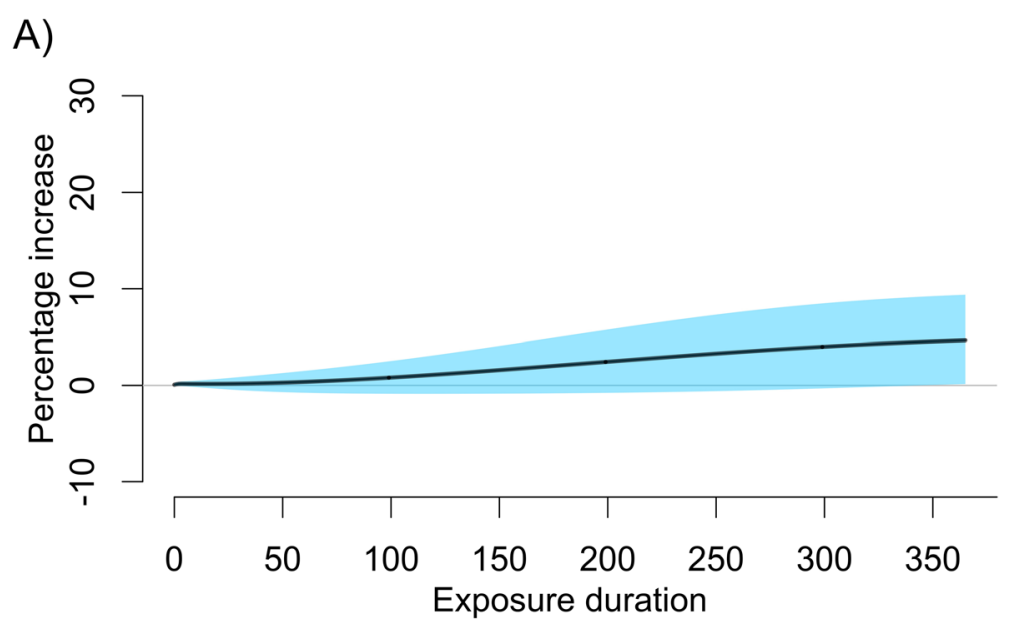

B)

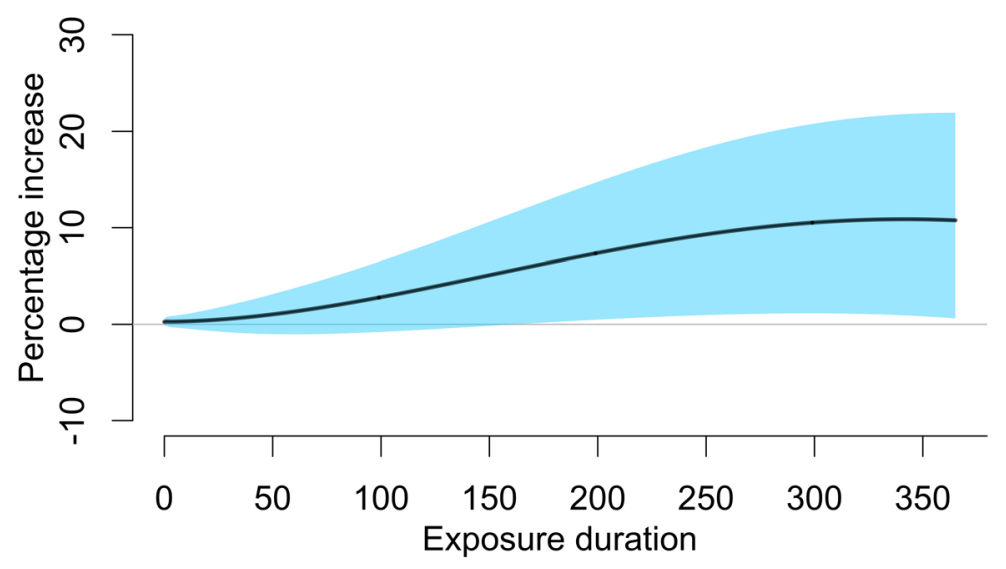

C)

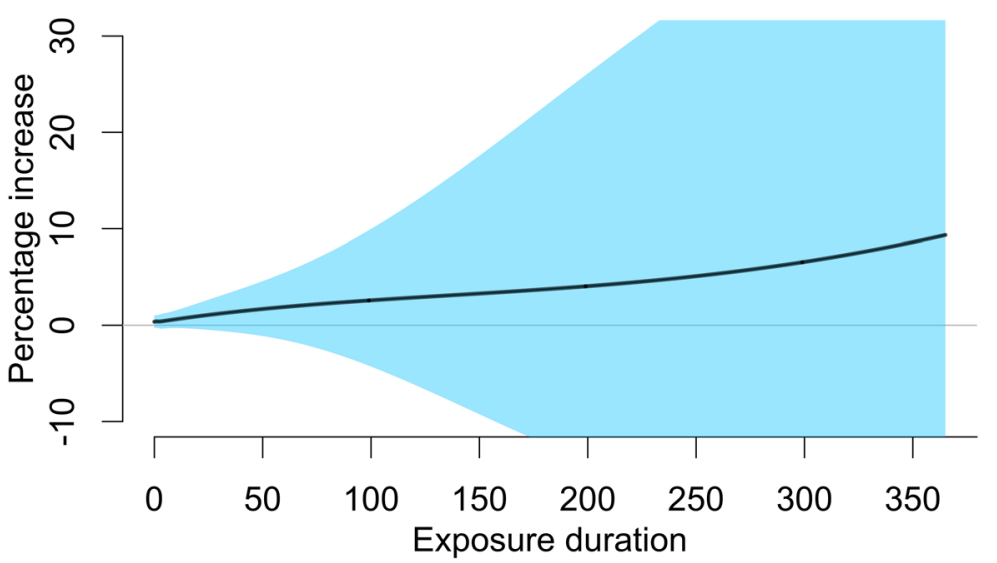

Fig. 4 Percentage increase of mortality risk per a $10 \mu \mathrm{g} / \mathrm{m}^{3}$ increase of $\mathrm{PM}_{10}$ by exposure duration in seven major cities of South Korea, $2006-$ 2013. a All-cause mortality. b Cardiovascular mortality. c Respiratory mortality

\section{Discussion}

We addressed a challenging issue in estimating the effect of long-term exposure on health outcomes using timeseries analysis - adjustment for seasonality and long- term time-trend that do not mask the effect and not reduce substantially variability of residuals of exposure series. $\mathrm{NCS}(t, p \mathrm{df} /$ year $)$ that is frequently used in timeseries studies may lead to very high standard errors, 

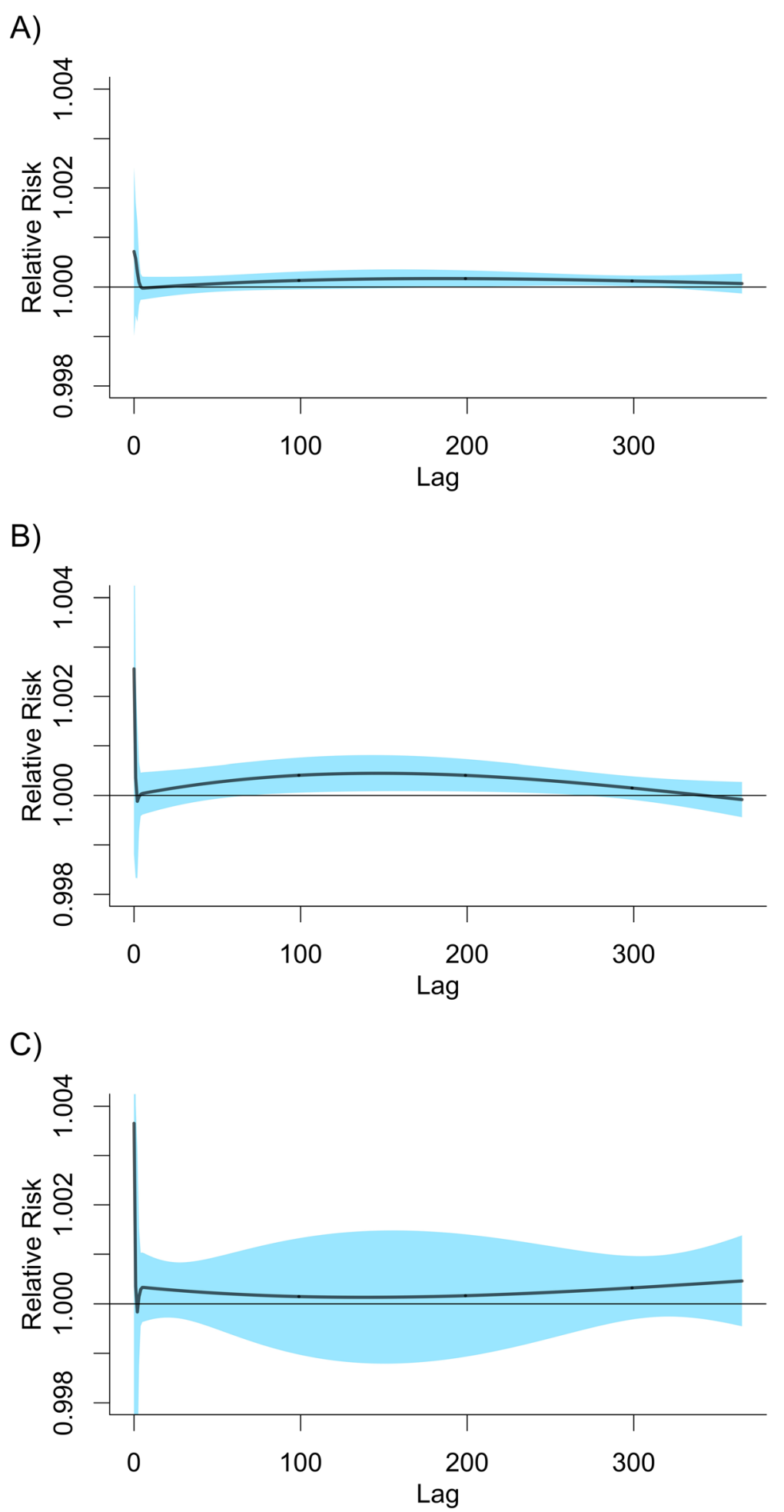

Fig. 5 Estimated lag patterns of the association between a $10 \mu \mathrm{g} / \mathrm{m}^{3}$ increase of $\mathrm{PM}_{10}$ and mortality in seven major cities of South Korea, 20062013. a All-cause mortality. b Cardiovascular mortality. c Respiratory mortality

which makes it difficult to infer the magnitude of the association between long-term exposure and health outcomes. Our results suggest that a combination of functions can be used to sufficiently adjust for seasonality and long-term time-trend and also allow for enough variability of residuals of exposure series, so that inflated 
standard errors can be avoided. We also showed that confounding by long-term exposure effects may arise in time-series studies for estimating short-term exposure effects; however, we postulate that this confounding might not be an issue for air pollution time-series studies because adjustment methods for seasonality and long-term time-trend could adjust for this confounding.

The effect of long-term exposure may be more likely to be confounded by seasonality and time-trend than that of short-term exposure. Higher df of NCS would provide stricter adjustment but reduce variability of residuals of exposure series. A combination of functions allows for higher variability of residuals of exposure series but may require additional adjustments for seasonality, depending on data applied, what covariates are measured and how they are adjusted. For example, deviations of seasonality in an outcome series may still exist even after distributed lags of environmental variables that has strong seasonality such as temperature [38] are adjusted. Other examples may include seasonality in an outcome series attributable to influenza epidemic and longer-term exposure than exposure of interest. Therefore, sensitivity analyses are recommended to determine sufficient but not redundant adjustment for seasonality, time-trend, and possible confounding by longer-term exposure as we did in our real-data analyses.

In line with the merits of sensitivity analyses, overfitting must be considered as it increases variance estimates and can yield highly variable estimates of an association. Sometimes, to our experience, statistically significant but spurious associations such as lag patterns of NCS (4 or 10df/year) in Fig. 3 may come out. To avoid overfitting, identification of residual variance of exposure series may be helpful, as in Table 1. Comparing lag patterns estimated across different lag models may also guide whether overfitting arises or not because highly variable estimates would come out from different lag models when standard errors of coefficient estimates of interest are inflated [13].

Some limitations are noted. We did not extend our focus into longer-term exposure beyond 1 year in realdata analysis. We found that functions of variables representing time explain to a larger extent the variability of longer-term fluctuation (e.g., 2 years) in an exposure series. Thus, there would be smaller variability of residuals of exposure series. This issue may be overcome with collecting more informative data. Second, we did not address exposure misclassification theoretically and analytically. So, we cannot rule out the possibility that exposure misclassification might affect exposure durations to different degrees (such as Figs. 4 and 5), but the overall impact on an estimate of the cumulative coefficient $\bar{\beta}$ might be toward the null $[7,8]$.
Nevertheless, an estimate affected by exposure misclassification in the context of personal exposure may be seen as an estimate of the effect of ambient air pollution in a given region that is of public health importance. For example, time-series analysis could be used to address cessation lag [39] of ambient air pollution exposures in a given population, which is a critical issue in understanding efficiency of ambient air pollution interventions. Changes of loss of life expectancy in that region as a measure of the severity of public health burden $[40,41]$ may also be estimated considering long-term exposure effect without cohort data [23].

\section{Conclusions}

We demonstrated that long-term exposure effects can be estimated using time-series analysis by addressing confounding by seasonality and long-term time-trend, while maintaining efficiency. Since maintaining efficiency may lead to less strict adjustment for seasonality and long-term time-trend, sensitivity analyses should be conducted to confirm that adjustment is sufficiently made. Rich case-only data such as death certificates and hospitalization records combined with repeated measurements of environmental determinants across countries would have high potentials for investigating the effects of long-term exposure on health outcomes allowing for unique contexts of local populations.

\section{Supplementary Information}

The online version contains supplementary material available at https://doi. org/10.1186/s12874-020-01199-1.

Additional file 1. Simulation methods and additional results of simulations. Figure S1. Two hypothetical observable lag patterns of the association between $1 \mu \mathrm{g} / \mathrm{m}^{3}$ increase of exposure to $\mathrm{PM}_{10}$ and mortality, used to generate simulation samples (the last row of panels). A) and B) Hypothetical actual effect (identical). C) Mortality displacement for a few days to several weeks for Observable lag pattern 1. D) Mortality

displacement for a few days to several weeks for Observable lag pattern 2. E) Mortality displacement for few days to two years for Observable lag pattern 1. F) Mortality displacement for few days to two years for Observable lag pattern 2. G) Observable lag patterns 1. H) Observable lag pattern 2. Figure S2. An example of simulated samples. A) all-cause death series. B) $\mathrm{PM}_{10}$ series. Table S1. Bias and Standard Deviation for the Association between a Two-Day Moving Average of $\mathrm{PM}_{10}$ (lag0-1) and All-Cause Mortality Estimated by a Model with Different Adjustment Methods for Seasonality and Long-Term Time-Trend over 5000 Samples

Additional file 2. Real data analysis methods and additional results. Table S2. Percentage increase and $95 \%$ confidence intervals of cardiovascular mortality risk per a $10 \mu \mathrm{g} / \mathrm{m}^{3}$ increase in two-day moving average of $\mathrm{PM}_{10}$ (lag0-1) or one-year distributed lags of $\mathrm{PM}_{10}$ (lag0-365) in seven major cities of South Korea, 2006-2013. Table S3. Percentage increase and $95 \%$ confidence intervals of respiratory mortality risk per a $10 \mu \mathrm{g} / \mathrm{m}^{3}$ increase in two-day moving average of $\mathrm{PM}_{10}$ (lag0-1) or oneyear distributed lags of $\mathrm{PM}_{10}$ (lag0-365) in seven major cities of South Korea, 2006-2013. Figure S3. Time-series of logarithm of daily all-cause deaths predicted by models with two different adjustments for seasonality and long-term time trend and their absolute differences. A) Timeseries in Seoul, 2006-2013 B) Absolute differences in Seoul. C) Time-series in Daegu, 2006-2013. D) Absolute differences in Daegu. Grey vertical 
dotted lines in B) and D) denote 80th, 90th, and 98th percentile of absolute differences. Figure S4. Results of additional sensitivity analyses in seven major cities of South Korea, 2006-2013. A) All-cause mortality. B) Cardiovascular mortality. C) Respiratory mortality. Percentage increases estimated by models with NCS(doy, 20df)+I(year)+NCS(week,

$3 d f$ )+NCS(month, 3df) in Table 3 (for all-cause mortality), Table S2 (for cardiovascular mortality), and Table S3 (for respiratory mortality) were duplicated for comparison (red triangles).

\section{Abbreviations}

$\mathrm{PM}_{10}$ : Particulate matter with aerodynamic diameter $\leq 10 \mu \mathrm{m}$; NCS: Natural cubic spline; df: Degrees of freedom; NCS(t,pdf/year): NCS of time $(t)$ throughout time-series (or the study period) with pdf per year; I(year): An indicator function of the order of year throughout time-series (or the study period); doy: Day of the year; NCS(doy,pdf): NCS of doy with $p d f$; NCS(week,pdf): NCS of the order of week throughout time-series (or the study period) with $p d f$; NCS(month,pdf): NCS of the order of month throughout time-series (or the study period) with $p d f$; SD: Standard deviation

\section{Acknowledgements}

None.

\section{Authors' contributions}

HK made the conception of the study, designed the study, collected the data, conducted the analysis, interpreted the results, wrote the draft and revised the manuscript. JTL collected data, interpreted the results, and revised the manuscript. KF interpreted the results and revised the manuscript. MB supervised the study, contributed to the conception, interpreted the results, and revised the manuscript. All authors have read and approved the manuscript.

\section{Funding}

This publication was developed under Assistance Agreement No. RD835871 awarded by the U.S. Environmental Protection Agency to Yale University. It has not been formally reviewed by EPA. The views expressed in this document are solely those of the authors and do not necessarily reflect those of the Agency. EPA does not endorse any products or commercial services mentioned in this publication. Research reported in this publication was also supported by the National Institute On Minority Health And Health Disparities of the National Institutes of Health under Award Number R01MD012769. The content is solely the responsibility of the authors and does not necessarily represent the official views of the National Institutes of Health.

\section{Availability of data and materials}

Daily number of deaths we used are not available without permission of Statistics Korea. City-level mortality data are publicly downloadable at the "Download service" section in MicroData Integrated Service (MDIS) by Statistics Korea (https://mdis.kostat.go.kr/index.do, in Korean) and more detailed mortality data can be purchased at the "Use Microdata" section in MDIS. Data for air pollution are publicly downloadable at the "Finally confirmed data" section in Air Korea (https://www.airkorea.or.kr/web, in Korean). Data for meteorological factors are publicly downloadable at the "Data" section in Data Portal by Korean Metrological Administration (https:// data.kma.go.kr/, in Korean). R codes for simulations and real-data analysis are provided in the first author's website, http://hkimresearch.com, or Github, https://github.com/HonghyokKim/AlternativeAdjustment.

\section{Ethics approval and consent to participate}

Not applicable. The data used in this study are daily number of deaths based on mortality registry in Statistics Korea. The authors have permission for this data from Statistics Korea.

\section{Consent for publication}

Not applicable.

\section{Competing interests}

The authors declare there is no any competing interests.

\section{Author details}

'School of the Environment, Yale University, 195 Prospect Street, New Haven, CT 06511, USA. BK21PLUS Program in 'Embodiment: Health -Society Interaction', Department of Public Health Science, Graduate School, Korea University, Seoul, Republic of Korea. ${ }^{3}$ School of Health Policy and Management, College of Health Science, Korea University, Seoul, Republic of Korea.

Received: 19 August 2020 Accepted: 21 December 2020

Published online: 04 January 2021

\section{References}

1. Bell ML, Samet JM, Dominici F. Time-series studies of particulate matter. Annu Rev Public Health. 2004;25:247-80.

2. Bhaskaran K, Gasparrini A, Hajat S, Smeeth L, Armstrong B. Time series regression studies in environmental epidemiology. Int J Epidemiol. 2013; 42(4):1187-95.

3. Atkinson R, Kang S, Anderson H, Mills I, Walton H. Epidemiological time series studies of PM2. 5 and daily mortality and hospital admissions: a systematic review and meta-analysis. Thorax. 2014;69(7):660-5.

4. Liu C, Chen R, Sera F, Vicedo-Cabrera AM, Guo Y, Tong S, Coelho MS, Saldiva PH, Lavigne E, Matus P. Ambient particulate air pollution and daily mortality in 652 cities. N Engl J Med. 2019;381(8):705-15.

5. Sera F, Armstrong B, Tobias A, Vicedo-Cabrera AM, Åström C, Bell ML, Chen B-Y, de Sousa Zanotti Stagliorio Coelho M, Matus Correa P, Cruz JC. How urban characteristics affect vulnerability to heat and cold: a multi-country analysis. Int J Epidemiol. 2019;48(4):1101-12.

6. Vodonos A, Awad YA, Schwartz J. The concentration-response between long-term PM2. 5 exposure and mortality; a meta-regression approach. Environ Res. 2018;166:677-89.

7. Zeger SL, Thomas D, Dominici F, Samet JM, Schwartz J, Dockery D, Cohen A. Exposure measurement error in time-series studies of air pollution: concepts and consequences. Environ Health Perspect. 2000;108(5):419-26.

8. Strickland MJ, Gass KM, Goldman GT, Mulholland JA. Effects of ambient air pollution measurement error on health effect estimates in time-series studies: a simulation-based analysis. J Exposure Sci Environ Epidemiol. 2015; 25(2):160-6.

9. Thurston GD, Kinney PL. Air pollution epidemiology: considerations in timeseries modeling. Inhal Toxicol. 1995;7(1):71-83.

10. Zanobetti A, Wand M, Schwartz J, Ryan L. Generalized additive distributed lag models: quantifying mortality displacement. Biostatistics. 2000;1(3):279-92.

11. Dominici F, Sheppard L, Clyde M. Health effects of air pollution: a statistical review. Int Stat Rev. 2003;71(2):243-76.

12. Costa AF, Hoek G, Brunekreef B, Ponce de Leon AC. Air pollution and deaths among elderly residents of Sao Paulo, Brazil: an analysis of mortality displacement. Environ Health Perspect. 2017;125(3):349-54.

13. Kim H, Kim H, Lee J-T. Spatial variation in lag structure in the short-term effects of air pollution on mortality in seven major south Korean cities, 2006-2013. Environ Int. 2019;125:595-605.

14. Schwartz J. Harvesting and long term exposure effects in the relation between air pollution and mortality. Am J Epidemiol. 2000;151(5):440-8.

15. Zanobetti A, Schwartz J, Samoli E, Gryparis A, Touloumi G, Atkinson R, Le Tertre A, Bobros J, Celko M, Goren A. The temporal pattern of mortality responses to air pollution: a multicity assessment of mortality displacement. Epidemiology. 2002;13(1):87-93.

16. Zanobetti A, Schwartz J, Samoli E, Gryparis A, Touloumi G, Peacock J, Anderson RH, Le Tertre A, Bobros J, Celko M. The temporal pattern of respiratory and heart disease mortality in response to air pollution. Environ Health Perspect. 2003:111(9):1188-93.

17. Goodman PG, Dockery DW, Clancy L. Cause-specific mortality and the extended effects of particulate pollution and temperature exposure. Environ Health Perspect. 2004;112(2):179-85.

18. Burnett RT, Dewanji A, Dominici F, Goldberg MS, Cohen A, Krewski D. On the relationship between time-series studies, dynamic population studies, and estimating loss of life due to short-term exposure to environmental risks. Environ Health Perspect. 2003;111(9):1170-4.

19. Gasparrini A. Modelling lagged associations in environmental time series data: a simulation study. Epidemiology (Cambridge, Mass). 2016;27(6):835.

20. Dominici F, McDermott A, Zeger SL, Samet JM. On the use of generalized additive models in time-series studies of air pollution and health. Am J Epidemiol. 2002;156(3):193-203. 
21. Goldman GT, Mulholland JA, Russell AG, Strickland MJ, Klein M, Waller LA, Tolbert PE. Impact of exposure measurement error in air pollution epidemiology: effect of error type in time-series studies. Environ Health. 2011;10(1):61.

22. Zeger SL, Irizarry R, Peng RD. On time series analysis of public health and biomedical data. Annu Rev Public Health. 2006;27:57-79.

23. Rabl A, Thach T, Chau P, Wong C. How to determine life expectancy change of air pollution mortality: a time series study. Environ Health. 2011; 10(1):25.

24. Peng RD, Dominici F, Louis TA. Model choice in time series studies of air pollution and mortality. J R Stat Soc. 2006;169(2):179-203.

25. Touloumi G, Samoli E, Pipikou M, Le Tertre A, Atkinson R, Katsouyanni K. Seasonal confounding in air pollution and health time-series studies: effect on air pollution effect estimates. Stat Med. 2006;25(24):4164-78.

26. Perrakis K, Gryparis A, Schwartz J, Tertre AL, Katsouyanni K, Forastiere F, Stafoggia M, Samoli E. Controlling for seasonal patterns and time varying confounders in time-series epidemiological models: a simulation study. Stat Med. 2014;33(28):4904-18.

27. Schwartz J, Zanobetti A, Bateson T. Morbidity and mortality among elderly residents in cities with daily PM measurements. Revised analyses of timeseries studies of air pollution and health; 2003. p. 25-58.

28. Pattenden S, Armstrong B, Milojevic A, Heal MR, Chalabi Z, Doherty R, Barratt B, Kovats RS, Wilkinson P. Ozone, heat and mortality: acute effects in 15 British conurbations. Occup Environ Med. 2010;67(10):699-707.

29. Guo Y, Gasparrini A, Armstrong BG, Tawatsupa B, Tobias A, Lavigne E, MdSZS C, Pan X, Kim H, Hashizume M. Heat wave and mortality: a multicountry, multicommunity study. Environ Health Perspect. 2017;125(8): 087006.

30. Armstrong BG, Gasparrini A, Tobias A, Sera F. Sample size issues in time series regressions of counts on environmental exposures. BMC Med Res Methodol. 2020;20(1):1-9.

31. Kim H, Lee J-T. On inferences about lag effects using lag models in air pollution time-series studies. Environ Res. 2019;171:134-44.

32. Pope CA, Brook RD, Burnett RT, Dockery DW. How is cardiovascular disease mortality risk affected by duration and intensity of fine particulate matter exposure? An integration of the epidemiologic evidence. Air Qual Atmos Health. 2011;4(1):5-14.

33. Brook RD, Rajagopalan S, Pope CA III, Brook JR, Bhatnagar A, Diez-Roux AV, Holguin F, Hong Y, Luepker RV, Mittleman MA. Particulate matter air pollution and cardiovascular disease: an update to the scientific statement from the American Heart Association. Circulation. 2010;121(21):2331-78.

34. Zanobetti A, Schwartz J. Mortality displacement in the association of ozone with mortality: an analysis of 48 cities in the United States. Am J Respir Crit Care Med. 2008:177(2):184-9.

35. Gasparrini A, Armstrong B, Kenward M. Multivariate meta-analysis for nonlinear and other multi-parameter associations. Stat Med. 2012;31(29):382139.

36. Perperoglou A, Sauerbrei W, Abrahamowicz M, Schmid M. A review of spline function procedures in R. BMC Med Res Methodol. 2019;19(1):46.

37. Gasparrini A, Armstrong B, Kenward MG. Distributed lag non-linear models. Stat Med. 2010;29(21):2224-34

38. Kim H, Bell ML, Lee J-T. Does a lag-structure of temperature confound air pollution-lag-response relation? Simulation and application in 7 major cities, Korea (1998-2013). Environ Res. 2017;159:531-8.

39. Walton H: Development of Proposals for Cessation Lag(s) for Use in Total Impact Calculations. Supporting paper for the 2010 COMEAP Report 2010, https:/assets.publishing.service.gov.uk/government/uploads/system/ uploads/attachment_data/file/304655/COMEAP_development_of_ proposals_for_cessation_lags.pdf.

40. Künzli N, Medina S, Kaiser R, Quenel P, Horak F Jr, Studnicka M. Assessment of deaths attributable to air pollution: should we use risk estimates based on time series or on cohort studies? Am J Epidemiol. 2001;153(11):1050-5.

41. McMichael AJ, Anderson HR, Brunekree B, Cohen AJ. Inappropriate use of daily mortality analyses to estimate longer-term mortality effects of air pollution. Int J Epidemiol. 1998;27(3):450-3.

\section{Publisher's Note}

Springer Nature remains neutral with regard to jurisdictional claims in published maps and institutional affiliations.

\section{Ready to submit your research? Choose BMC and benefit from}

- fast, convenient online submission

- thorough peer review by experienced researchers in your field

- rapid publication on acceptance

- support for research data, including large and complex data types

- gold Open Access which fosters wider collaboration and increased citations

- maximum visibility for your research: over $100 \mathrm{M}$ website views per year

At $\mathrm{BMC}$, research is always in progress.

Learn more biomedcentral.com/submissions 